\section{Premiums and Discounts for Plant Patents and Trademarks Used on Ornamental Plant Cultivars: A Hedonic Price Analysis}

\author{
Jennifer Drew ${ }^{1}$ \\ Department of Applied Economics, University of Minnesota, Twin Cities, \\ 1994 Buford Avenue, St. Paul, MN 55108
}

\author{
Chengyan Yue ${ }^{2,5}$ \\ Department of Horticultural Science and Department of Applied Economics, \\ University of Minnesota, Twin Cities, 1970 Folwell Avenue, St. Paul, MN \\ 55108 \\ Neil O. Anderson ${ }^{3}$ \\ Department of Horticultural Science, University of Minnesota, Twin Cities, \\ 1970 Folwell Avenue, St. Paul, MN 55108
}

\author{
Philip G. Pardey ${ }^{4}$ \\ Department of Applied Economics, University of Minnesota, Twin Cities, \\ 1994 Buford Avenue, St. Paul, MN 55108
}

Additional index words. intellectual property, marketing, ornamental plants

\begin{abstract}
The value and role of intellectual property (IP) rights pertaining to plant innovations and their economic consequences on plant values is largely unknown. A hedonic pricing model was adapted to the characteristics of the U.S. wholesale ornamental plant market, specifically the bedding, garden plant and nursery plant markets, to analyze two forms of IP rights used on plants (i.e., plant patents and trademarks). By controlling plant-specific attributes and a variety of market variables that might affect plant values, our empirical analysis reveals sizable price premiums for plant patents that may have been masked in other studies. As expected, plant patent premiums vary considerably between species where the costs of producing and marketing new cultivars differ greatly. Surprisingly, we find that the use of trademarks have a negative effect on plant prices.
\end{abstract}

In the United States, the number of plant varietal rights applications per year has grown rapidly, particularly in the past 20 years. As of 2010, the total of all these varietal rights were 34,559 with plant patents ( $61 \%$ of the total), plant variety protection (PVP, 20\%), and utility patents (10\%). Both agricultural and horticultural plants have, on average, experienced similar growth rates in the past 20 years, and the largest portion (71\%) of plant varietal IP rights is for horticultural plants. Plant patents are $61 \%$ of all varietal rights and virtually all are for horticultural plants (Drew, 2010). Ornamental plants account for $77 \%$ of all horticultural

Received for publication 15 Oct. 2014. Accepted for publication 9 Mar. 2015.

${ }^{1} \mathrm{PhD}$ graduate.

${ }^{2}$ Associate Professor and Bachman Endowed Chair in Horticultural Marketing.

${ }^{3}$ Professor.

${ }^{4}$ Professor and Director of University of Minnesota's International Science and Technology Practice and Policy (InSTePP).

${ }^{5}$ To whom reprint requests should be addressed; e-mail yuechy@umn.edu.
IP rights and $84 \%$ of all plant patents (Drew, 2010). The steady growth of bedding and gardening plant rights is the driver of the growth of ornamental rights. Bedding plants accounted for $12 \%$ of all plant patents in 1980 and the share has increased to $60 \%$ in 2008 (Drew, 2010). In contrast, for the same period, the number of IP rights for nursery industry plants remained fairly constant and had an approximate share of $13 \%$ of all rights. Ornamental plants primarily use plant patents, the oldest form of IP for plants in the United States (Drew, 2010).

Likewise, the horticultural markets, in particular, ornamental markets, have also grown in real value of production. Horticultural crop value of production grew from $19 \%$ of all agricultural crops in 1924 , to $40 \%$ in 2004 (Drew, 2010). Of the major horticultural crop groups (i.e., fruit and nuts, vegetables, and greenhouse and nursery), ornamental crops of the greenhouse and nursery industries had the fastest and steadiest growth. Since the early 1990s, the nursery and bedding/ gardening plant industries have remained the largest growing ornamental sectors (Drew, 2010; Jerardo 2007).
Coinciding with the increases in plant IP and growing markets, the number of commercially available cultivars of horticultural plants in Canada and the United States have increased from $\approx 29,000$ in 1987 to $\approx 107,000$ in 2010 (Drew et al., 2010; Isaacson and Allen, 2010). Recently, in addition to plant patents, there has been a rapidly growing effort to brand these high-valued ornamental crops and gain additional value premiums from the protection of cultivar innovations via other forms of legal protection such as trademarks (Aguirre, 2006; Schoellhorn, 2009). There has been a lack of consistency in how trademarks are used in connection with cultivar names where proper use, marketing, policing, and ingenuity are required to generate additional value from trademarks (Aguirre, 2006). In addition, the difficulties in maintaining quality standards in plant products have negative effects on branding programs.

Most prior studies have failed to empirically reveal any significant or sizable effects of IP rights for plant cultivars. Several studies (Alston and Venner, 2002; Butler and Marion, 1985; Penna, 1994; Perrin et al., 1983; Stallmann, 1986) analyzed the welfare effects of IP rights for plants through research and development (R\&D) investment and increases of new cultivars. Overall crops these studies showed the effects were weak to nonexistent with some finding significant effects on just a few crops such as increased breeding efforts for soybeans (Perrin et al., 1983), increased investment in R\&D for selfpollinated wheat and soybeans (Butler and Marion, 1985; Knudson and Pray, 1991), and increased cultivar releases in roses and strawberries (Penna, 1994). Stallmann (1986) found that woody crops were particularly unaffected by the institution of plant patents due to the lengthy breeding process and difficulties in detecting infringement. Welfare analysis of the quality changes from the institution of PVP in 1970 reveals yields for soybeans increased slightly with PVP (Perrin et al., 1983) and showed no significant change in wheat varieties (Alston and Venner, 2002). Rangnekar (2002) found that quality changes were systematically small and posited that this was a form of planned obsolescence. Studies of price effects of PVP show IP for plants to have slight (Alston and Venner, 2002; Hansen and Knudson, 1996; Lesser, 1994) to substantial effects (Butler and Marion, 1985 ) with price gains diminished by farmersaved seeds (Hansen and Knudson, 1996). Perhaps, the revealed size of the effects of IP for plants has been small because the research is dominated by studies specific to food crops and agricultural crops derived from biotechnology.

In the United States, plant breeders can protect their inventions with a plant patent (asexually propagated plants), PVP certificate (sexually propagated plants or tuberous asexually propagated crops such as potatoes), or a utility patent (plants, genes, or germplasm for asexually or sexually propagated crops). For more information, refer to "The 
Roots and Fruits of Plant Varietal Rights: an Economic Evaluation of Intellectual Property Rights in the US Horticultural Sector" (Drew, 2010). Of the three forms of IP for plants, the plant patent is the most prevalent in the ornamental plant industry and has been in use since the 1930 Townsend-Purcell Plant Patent Act (Drew, 2010). Commonly used on horticultural plants before 1930, trademarks were abandoned with the introduction of plant patents (Stallmann, 1986), and only until recent years have regained popular use, often in conjunction with the plant patent (Aguirre, 2006; Schoellhorn, 2009).

An economic criticism of varietal IP rights of the plant patent and PVP is that the protection offered may be too weak to provide incentive in developing new cultivars (Butler and Marion, 1985; Lesser, 1994; Penna, 1994; Stallmann, 1986). In addition, the effects of the rights are different between crops (Butler and Marion, 1985; Penna 1994; Stallmann, 1986). Stallmann (1986) theorized that these differences could be due to plant differences that affect breeding, production/ marketing costs, and costs of enforcing the plant patent such as a longer juvenile period, greater space requirements, stability of reproduction, greater uncertainties with respect to research success, and market acceptance. For a pertinent example, woody species, in particular tree species, have longer juvenile periods and greater space requirements which increase breeding and reproduction costs. In addition, they are durable and last for months or years; consumers tend to be reticent in replacing existing plants in their landscapes. The higher costs and stability of reproduction associated with woody plants can give competitive growers an incentive to infringe on plant IP rights (Stallmann, 1986).

Ornamental plant marketing involves a complex flow of new and existing plant cultivars and information through market channels (Drew et al., 2010). Vertical production stages for plant products begin with the production of new cultivars via independent public and private sector plant breeders and plant introduction firms and end with consumer purchases of plant products. Ornamental plants are bred with specific target breeding attributes (phenotypes) such as size, shape, form, texture, and flower/foliage color (Anderson, 2006). Producer firms propagate new cultivars, many of which are patented, branded or both, along with other cultivars to sell in the wholesale market. These firms may also supply new cultivars either as a byproduct of their activities or through an "in house" breeding facility. Marketing studies of wines have shown that firm reputation is important for selling agricultural products because these products have many attributes that are not readily known to the buyer (Ali et al., 2008; Schamel, 2003; Schamel and Anderson, 2003). Ornamental firm reputations are built upon highly variable and difficult to ascertain attributes such as customer service, quality of product (particularly innovative qualities), cultivar selection, and plant performance.
On the other side of the wholesale market are growers, retailers, and landscapers. Wholesale buyers choose plant cultivars based on expected plant health and quality, plant offering size, form and price, growing requirements, shipping costs, which plants are offered through their broker, anticipated consumer preferences, and the level/effectiveness of promotions.

Recent structural developments in the ornamental industry may be in response to the relatively weak IP rights inherent in a plant patent. Royalty administration companies with an international reach, act as agents for breeders matching markets to new cultivars, policing cultivar IP rights, and administering the collection and distribution of royalties (Aguirre, 2006). Marketing firms have emerged to aggressively promote a nursery's or a group of nurseries' newer plant cultivars. These firms orchestrate the marketing approach throughout the distribution chain, which includes trademarking, branding, and licensing agreements that assure plants are produced to prescribed quality standards, sold with required tags, and plants with patents are not propagated without authorization (Aguirre, 2006). If these efforts are effective, they reduce the time it takes for a new cultivar to be adopted in both wholesale and retail markets, and increase the incentives, through premiums, for firms and individual breeders to innovate.

The objectives of this article focus on the value of IP rights for ornamental plants of the horticultural sector where there are higher per-unit prices and considerable effort and expense go into seeking and exercising plant varietal IP rights for horticultural plants. We re-examine the role of IP rights pertaining to plant innovations and assesses the economic consequences of IP rights for plants by analyzing their impacts on plant values using the hedonic price framework. A hedonic pricing model is adapted to the U.S. wholesale ornamental plant market and, in particular, the bedding and garden plant and nursery plant markets to analyze two forms of IP rights used on plants (i.e., the plant patent and the trademark). By controlling plant-specific attributes that might affect plant values such as the type of plant, size, form, growth habit, resistance to biotic and abiotic stresses, and a variety of marketing variables such as the size and form of the marketed plant, our empirical analysis will determine the price premium effects of the plant patent that may have been masked in previous studies of IP rights for plants. Premiums from the use of trademarks are more modest, but when used in conjunction with the plant patent may decrease plant value depending on the species. By fitting our hedonic model using a multiple equation approach and fitting a hedonic price equation for each species, we can test for significant differences between species in price premiums and discounts for IP used on plants, as well as address several specification issues prevalent in hedonic literature (i.e., collinearity, heteroskedasticity) (Unwin, 1999).
Unlike many hedonic models, ours is not driven by the availability of data, but is a model for which the data were collected.

\section{Materials and Methods}

The hedonic framework. To the best of our knowledge, Lesser (1994) is the only published research that used the hedonic pricing approach to examine the price premium implications of PVP certificates on 43 cultivars of soybean seed marketed in New York. Waugh (1928), who developed and used the hedonic approach with a price analysis of vegetables in the Boston wholesale market, derived implicit prices for product attributes. Court (1939) and, in particular, Griliches (1961) revived and popularized the hedonic framework in applications to the automobile industry that sought to develop automobile price indices which took into account product quality changes. The hedonic framework's flexibility has been demonstrated with evaluations of a wide variety of agricultural product attributes including less tangible quality attributes such as the vintage of wine (Byron and Ashenfelter, 1995), firm reputation for wine (Schamel, 2003; Schamel and Anderson, 2003), organic attributes for breakfast cereal (Stanley and Tschirhart, 1991) and produce (Lin et al., 2008) as well as fair-trade attributes for coffee (Maietta, 2003).

For our model, we define the two sides of the hedonic market as suppliers and users of input products where wholesale sellers and buyers produce and use a wide array of differentiated ornamental plants. Following language similar to Triplett (1990), we adapt Rosen's hedonic framework (1974) for consumer goods to a hedonic framework for inputs for production. Rosen (1974) defines the hedonic framework as an equilibrium relation between consumer utility (user's input production) and production functions (supplier's input production). As with Rosen's hedonic model, we assume attributes of ornamental plant goods (inputs) rather than the goods themselves are the true arguments of the utility function (true inputs to the production function). Thus, it is implied that the heterogeneous plant inputs are aggregations of attributes:

$$
Q=Q(a, Z)
$$

where $Q$ is scalar output, $Z$ is a vector of other goods, which we assume to be homogenous goods (productive inputs such as heat, water, fertilizer), and for expositional simplicity we specify only one heterogeneous good, the ornamental plant, in the system with characteristics $(a)$. For ease of theory exposition we can write as follows

$$
Q=Q(q(a), Z)
$$

where $q(\cdot)$ is an aggregator function of attributes $(a)$ that are embodied in all the heterogeneous plant input the grower uses in production. Likewise, for the input producer, production of a heterogeneous input is the joint output of the set of attributes embodied in that plant input. 
The economic behavior of buyers and sellers of heterogeneous plant inputs can be described by sets of demand and supply functions for attributes. These demand and supply functions are derived from the optimization of buyer's and seller's profit functions of attributes. On the demand side, $q(\cdot)$, contains information about preferences (production technologies) and the hedonic price function, $p(a)$, provides information about the price surface.

Rosen (1974) showed that if there are $n$ competitive buyers, with dispersions in tastes (production technologies), the hedonic price function $p(\cdot)$, will trace out an envelope to the set of preferences (production technologies), described by the $n$ aggregator functions, $q_{1}(\cdot), \ldots, q_{n}(\cdot)$. We assume as with most envelopes, the form of $p(\cdot)$ is an independent of the form of $q(\cdot)$, and is determined on the demand side by the distribution of buyers across attributes space. Likewise, a parallel condition exists on the seller side of the market. The hedonic function is a price surface in attributes space.

Database creation. A cultivar-specific price database was developed which required careful collecting and merging data from several and, not always immediately compatible, data sources. The sampling design was structured to include sufficiently large numbers of observations with a relatively complete set of plant attributes (Drew, 2010).

Fifteen species were chosen for this research: Acer (maple), Rhododendron (azalea), Clematis, Coreopsis, Echinacea (cone flower), Hemerocallis (daylily), Heuchera or Heucherella, Hibiscus, Hosta, Hydrangea, Ilex (holly), Juniperus (juniper), Phlox, Rosa (rose), and Spiraea. These species represent popular, higher-valued plant types (Acer, Rhododendron, and Rosa are the highest valued market segments; USDA, 2000), and include several species known to entail substantial breeding or patenting efforts (Rosa, Rhododenrdron, and Hibiscus with the most plant patents). In addition, a balance was struck between woody and herbaceous perennial species, as well as older established and newly popularized crops. Attributes were researched and entered for 2242 different cultivars. For each cultivar, a broad range of phenotypic attributes were collected, as well as information on the cultivar's IP status, branding, and promotional details.

Nine propagation firms were chosen from the largest nursery and herbaceous perennial plant producers serving the U.S. plant market whose total annual sales exceed $\$ 10$ million. They are Greenleaf Nurseries, Monrovia Nursery, Bailey Nurseries, Zelenka Nursery, Walters Gardens, Inc., Yoder Green Leaf, Sawyer Nursery, Fisher Farms, and Creek Hill Nursery. The abbreviated version of the firm names will be used. The objective was to obtain a set of firms from which the price data for the widest selection of the targeted plant species could be obtained. Firms were also chosen to achieve a balanced list in terms of types of plants produced and a balance between herbaceous perennial and woody nursery products. Zelenka, Walters, Sawyer, and Creek Hill are primarily perennial plant producers, and Greenleaf, Bailey, and Zelenkaand Fisher are primarily nursery plant producers while Monrovia is a strong perennial and nursery plant producer. Most of the chosen firms cooperated by directly supplying their printed catalogs or listed prices. The remaining data were obtained from the University of Minnesota's Andersen Horticultural Library or online catalogs. Price data for each firm was collected for the years 2005, 2006 , and 2007. The primary data set compiled consisted of 21,200 observations. An observation is one plant of a specific cultivar which is offered in a particular size and form by a specific firm in a specific year. In any specific year, a firm may offer as few as zero or one or, as for some popular maple and juniper trees, as many as 35 different offerings (observations) for a plant cultivar.

The cultivar-specific attribute data and the wholesale market price data were collected as two separate sets and entered in a relational database (Microsoft Access). A variety of cross tabulations, scanning subpopulations, and box plots were used on the combined data (i.e., species, firms, woody plants, herbaceous perennials) to identify extreme values and correct for errors. Recorded values were checked against the original data sources to correct for any inaccuracies. A total of 76 observations were removed due to unresolved errors.

The final data set consists of 21,124 price observations for 2242 different cultivars. About 184 dummy variables and a few integer and continuous variables were constructed to fit a hedonic model. The dependent price variable was constructed from wholesale prices for every plant offering. The data includes an indicator variable for plant patents to indicate if the cultivar has an active plant patent or a plant patent pending at the time of observation. A plant patent age variable was constructed using the date of application for the plant patent for all observations with a valid, expired, or pending patent. An indicator trademark variable was constructed for analysis that indicates whether the cultivar had a name trademark or is part of a trademarked series in 2007. It is assumed that, if the name trademarks were used in 2007, they were also in use during 2005 and 2006. The numbers of trademarked and nontrademarked promotions were used to construct an integer variable for each type of promotion. Trademarked promotions include breeder, market association, market firm, and producer firm plant collections with branding schemes used to associate the cultivar with a particular desirable set of attributes. Nontrademarked promotional information includes breeder names, nursery of origin names, and notations of popularity. Also included is an indicator if the cultivar name was registered through a prominent plant association. A set of firm indicator variables were included as a measure of firm reputation. Some of the firms included have a trademarked firm name or logo. For this article, we do not investigate their promotional value.

Many control variables were constructed from plant offering and plant cultivar information that were deemed a priori as valued plant attributes. Offering variables included variables to describe offering type, size, form, and grade for each observation.

These data include many phenotypic attribute variables specific to individual cultivars, many of which relate directly to productivity for both seller's plant inputs and buyer's plant outputs. Included are some variables that are more generally applicable such as growth rate (slow, medium, and fast), mature height (in feet), and growth forms (i.e., columnar, pyramidal, and round). Tolerance indicator variables such as pest resistance, sun tolerance and salt tolerance were combined to form a resiliency rating variable. Consumer use indicator variables such as container and hedge plants were combined to form an end-use rating variable.

These data are complex and hierarchical in structure. For one of the nine firms, there may be several offerings/observations (i.e., with different sizes and forms) of a particular cultivar belonging to one of the 15 species in 1 of 3 years. The number of observations and the number of different cultivars vary across firms. Due to the data structure, the data can be grouped along several levels, according to year, firm, and species. Species and firms can be grouped according to their plant type or plant type of specialization: woody or herbaceous perennial, because each cultivar offering is categorized as such (Tables 1 and 2). There is an uneven distribution of observations between woody and herbaceous perennial plants and, in particular, with IP over firms (Table 1) and species groups (Table 3 ). More details and summary statistics regarding this data are available (cf, Drew, 2010).

Nineteen percent of the plants have plant patents, 23\% have trademarked names and $14 \%$ have both plant patents and trademarked names (Tables 2 and 3 ). The mean plant price is $\$ 13.22$ and the mean price varies greatly between species ranging from $\$ 1.58$ for Phlox to $\$ 33.95$ for Acer. From the mean prices for plants with a plant patent $(\$ 12.41<$ $\$ 13.22)$, with a name trademark (\$16.77), and with both a plant patent and a name trademark (\$14.38), it might be possible that the value contribution to price from the name trademark may be higher than that from the plant patent and that there is a price discount from the plant patent. Also, it appears that the addition of the trademark name to a plant patent increases the plant's value.

Statistical mean prices for IP variables of the price data stratified by species groups, reveal a more complex picture (Table 3 ). Controlling for species, the average unit price for patented plants exceeds the average unit price for plants with no patent except for Hibiscus and Juniperus, and exceeds the average unit price for seven of the 13 species that have trademarked plants. Controlling for species, the mean price for 10 of the 13 
Table 1. Ornamental price data structure of observations by firm [nine firms and pooled (All Firms)], plant type (woody perennial, herbaceous perennial, all types, total observations) and intellectual property (IP) [plant patents (PP), trademark name (TM), both PP and TM, IP share of firm observations, observations with IP].

\begin{tabular}{|c|c|c|c|c|c|c|c|c|c|}
\hline \multirow[b]{4}{*}{ Firm } & \multicolumn{4}{|c|}{ Plant type } & \multicolumn{5}{|c|}{ Intellectual property } \\
\hline & $\begin{array}{l}\text { Woody } \\
\text { perennial }\end{array}$ & $\begin{array}{c}\text { Herbaceous } \\
\text { perennial }\end{array}$ & $\begin{array}{c}\text { All } \\
\text { types }\end{array}$ & $\begin{array}{c}\text { Total } \\
\text { observations }\end{array}$ & PP & $\mathrm{TM}$ & $\begin{array}{l}\text { Both PP } \\
\text { and TM }\end{array}$ & $\begin{array}{c}\text { IP share of firm } \\
\text { observations }\end{array}$ & $\begin{array}{c}\text { Observations } \\
\text { with IP }\end{array}$ \\
\hline & \multirow{2}{*}{\multicolumn{2}{|c|}{$\begin{array}{c}\text { Share of firm total } \\
\text { observations }(\%)\end{array}$}} & \multicolumn{2}{|c|}{ Share of total observations } & \multirow{2}{*}{\multicolumn{3}{|c|}{$\begin{array}{c}\text { Share of firm total } \\
\text { observations }(\%)\end{array}$}} & \multicolumn{2}{|c|}{ Share of total observations } \\
\hline & & & $\%$ & Count & & & & $\%$ & Count \\
\hline All firms & 70.3 & 29.7 & 100.0 & 21,124 & 19.5 & 23.5 & 13.9 & 29.0 & 6,126 \\
\hline Greenleaf Nursery Company & 87.8 & 12.2 & 23.0 & 4,855 & 22.0 & 29.4 & 18.1 & 33.3 & 1,618 \\
\hline Monrovia Nursery & 72.8 & 27.2 & 17.2 & 3,639 & 16.3 & 22.0 & 11.9 & 26.4 & 961 \\
\hline Bailey Nurseries & 84.7 & 15.3 & 25.1 & 5,295 & 22.9 & 31.4 & 18.3 & 36.1 & 1,911 \\
\hline Zelenka Nursery & 72.8 & 27.2 & 13.6 & 2,875 & 19.9 & 25.8 & 15.3 & 30.4 & 874 \\
\hline Walters Gardens, Inc. & 0.2 & 99.8 & 5.7 & 1,207 & 16.2 & 1.3 & 1.3 & 16.2 & 195 \\
\hline Yoder Green Leaf & 15.2 & 84.8 & 4.0 & 846 & 24.2 & 8.7 & 6.7 & 26.2 & 222 \\
\hline Sawyer Nursery & 0.0 & 100.0 & 4.1 & 866 & 3.5 & 0.9 & 0.9 & 3.5 & 30 \\
\hline Fisher Farms & 92.3 & 7.7 & 5.7 & 1,209 & 11.7 & 16.3 & 9.8 & 18.2 & 220 \\
\hline Creek Hill Nursery & 34.0 & 66.0 & 1.6 & 332 & 26.8 & 8.1 & 6.3 & 28.6 & 95 \\
\hline
\end{tabular}

Data source: "Ornamental Plant Producer Price Data” (Drew, 2010).

Table 2. Ornamental plant price data summary statistics (variable, means $\pm \mathrm{SD}$ ) and short descriptions for plants and firms used in the present study.

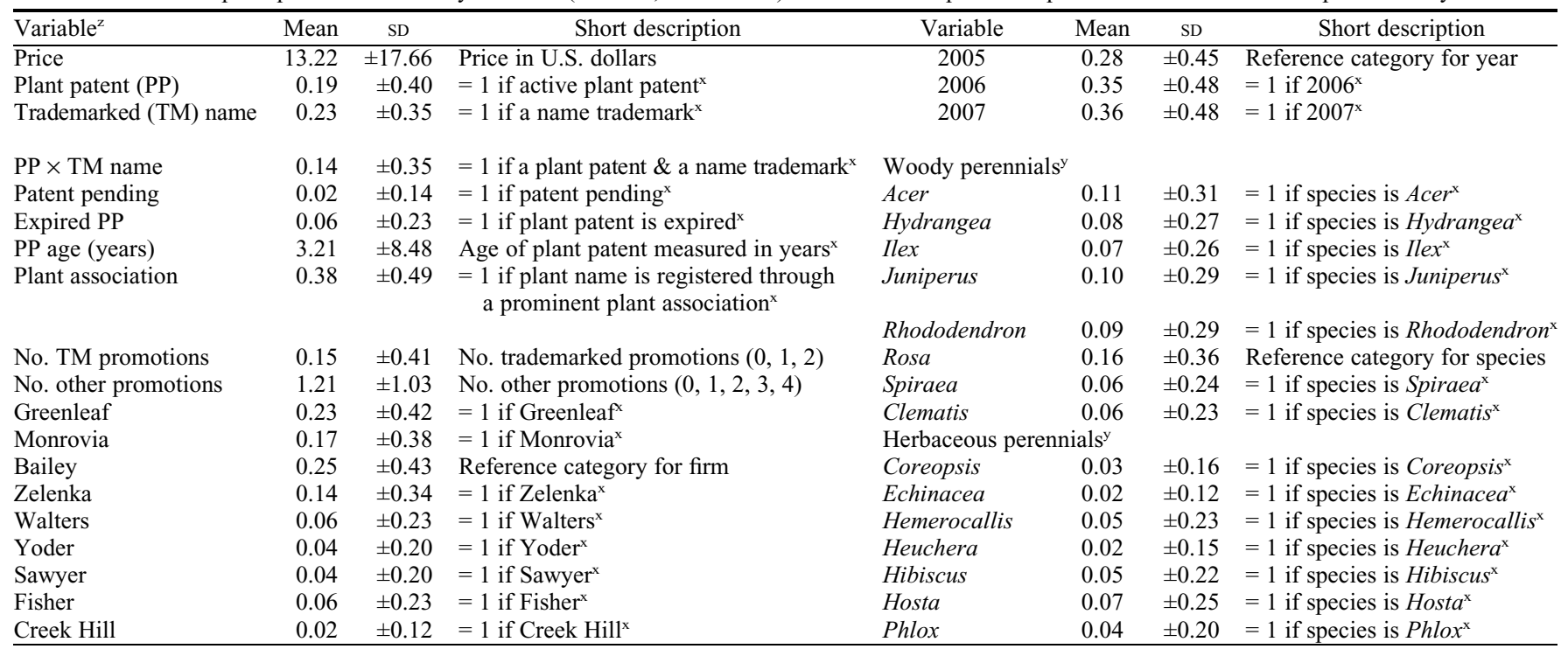

${ }^{2}$ Designates which perennial species are woody and which nurseries offer mostly woody perennial species. Acer, Hydrangea, Ilex, Juniperus, Rhododendron, Rosa, and Spiraea are all woody species; some Hibiscus and Clematis vines are woody.

${ }^{y}$ Denotes which species are herbaceous and which nurseries offer mostly herbaceous perennial species.

${ }^{\mathrm{x}} 0$ otherwise.

Data source: “Ornamental Plant Producer Price Data” (Drew, 2010).

species that have both a plant patent and a name trademark is higher than the mean price of plants with just plant patents. It is interesting to note that the conditioned mean prices for woody plants (Acer, Hydrangea, Ilex, Juniperus, Rhododendron, Rosa, and Spiraea) with every combination of trademark names and plant patents are higher (except for Clematis) than mean prices for nonwoody or herbaceous plants (Coreopsis, Echinacea, Hemerocallis, Heuchera, Hibiscus, Hosta, and Phlox).

Model specification. The hedonic price model $p(a)$ described in the previous section reflects both supply and demand influences. For empirical analysis, the basic hedonic equation for this article can be expressed as

$$
\begin{aligned}
P= & \alpha+\sum_{s} \beta_{s} \mathrm{IP}_{s}+\sum_{u} \gamma_{u} \mathrm{MKT}_{u} \\
& +\sum_{v} \delta_{v} \mathrm{PLT}_{v}+\varepsilon
\end{aligned}
$$

where, IP represents a set of IP attributes of ornamental plants; MKT represents a set of market attributes such as plant offering sizes and forms and firm fixed effects; PLT is a set of plant cultivar attributes.

Choosing the correct functional form for the estimation of the hedonic price function has been an ongoing issue for hedonic empirical estimation because there is no a priori theory that reveals the appropriate functional form (Rosen, 1974). Previous studies have used and argued for the use of various functional forms, including the linear, semi$\log$, and the flexible functional form of a Box-Cox transformation model (Estes, 1986; Estes and Smith, 1996; Huang and Biing-Hwan, 2006; Palmquist, 1984). The choice of the functional form for the hedonic price equation remains an empirical yet fundamental issue.

A semilog model was chosen to estimate the hedonic equation. Diewert (2003) argued that the residuals from a logarithmic hedonic model are less likely to be heteroskedastic than those from a linear model. In addition, semilog allows for coefficients to measure the percentage contribution to price with the presence of an attribute represented by an indicator variable or with a per unit change in an integer or continuous variable.

A careful procedure for specifying the basic regression model began with a small set of regressors that were a priori deemed essential. The stepwise regression-added regressors were checked for multicollinearity using a procedure developed by Belsley et al. (1980). Simultaneously, coefficients were assessed for their stability in size and sign. In addition, the $\mathrm{R}^{2}$ and AIC statistics were used to compare the explanatory power of nested models. Cultivar attribute variables were not included in this basic model because of colinearity issues with the species attributes, and the Ramsey (1969) RESET test indicated the model was fully specified without cultivar attributes. A summary of all the control variables is available upon request from the authors. An additional analysis using leverage scores was used to determine if the outlier data had undue influence on the coefficient estimates. Leverage measures the multivariate distance between the explanatory 
Table 3. Average unit prices (US dollars, \%) stratified by species (herbaceous and woody) and intellectual property (with/without plant patent, trademark name and both) attributes.

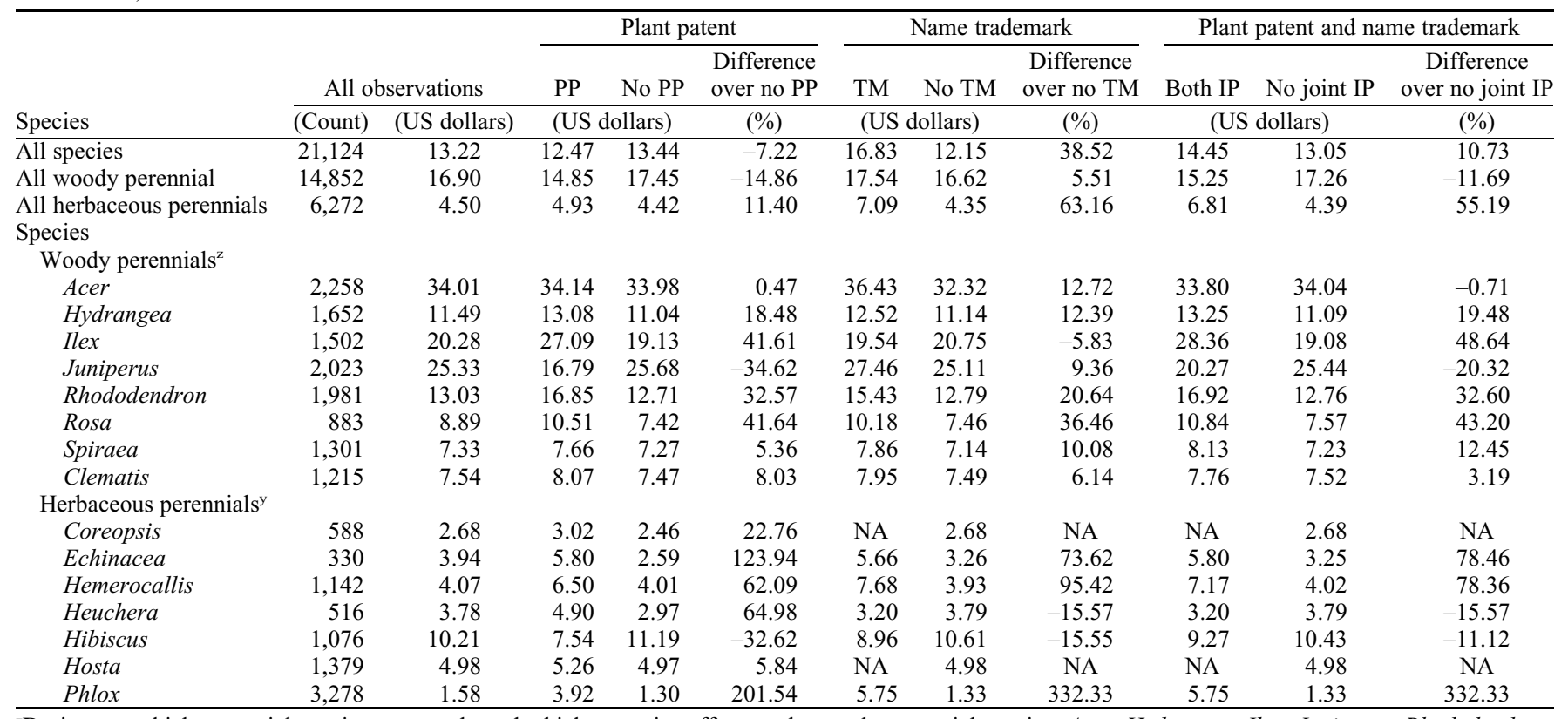

${ }^{2}$ Designates which perennial species are woody and which nurseries offer mostly woody perennial species. Acer, Hydrangea, Ilex, Juniperus, Rhododendron, Rosa, and Spiraea are all woody species; some Hibiscus and Clematis vines are woody.

${ }^{y}$ Denotes which species are herbaceous and which nurseries offer mostly herbaceous perennial species.

These data reflect 3 years $(2005,2006$, and 2007) of wholesale market prices, calculated as real 2006 dollars using U.S. consumer price indices (USDL, 2010). Data source: "Ornamental Plant Producer Price Data" (Drew, 2010).

variables for observation $k$ and the average of all observations, accounting for the correlation structure. Leverage scores showed that no observation's residuals exceeded a 0.2 cutoff indicating that no outliers would have a significant consequence on the coefficients or in the predicted values.

The fitting of the basic model tested and explored a semilog functional form to be used to estimate a common set of parameters to all observations of the data. Implicitly, this model assumes that the different explanatory variables have independent, additive, and fixed effects (for the indicator variables only) on the dependent variable which may not be true considering the structure of the data. In fact, the plant price data more closely resemble data which are hierarchical in nature with the firm as the primary sampling unit and the species as the stratum within each primary sampling unit. A Breusch-Pagan a.k.a. Cook-Weisberg test indicated that heteroskedasticity was strongly an issue with this basic model. The $\chi^{2}$ statistic was 276.72 with $1 \mathrm{df}$.

The species groups and firm groups are suspected of presenting the strongest influence of heteroskedasticity. In addition, the summary statistics of price over IP variables and between species and firms suggest that the IP coefficients may also vary between species and firms. Since most of the variation may be due to whether the observation is a woody or herbaceous perennial species and species groupings can be identified as mostly either woody or herbaceous perennial groupings, separate equations are estimated using ordinary least squares (OLS) for each species.

Even if we use separate species equations to accommodate for the heteroskedasticity resulting from the different species, there may be some remaining heteroskedasticity due to the different firms. In addition, such data sets are also subject to violations of the assumption of statistical independence of observations. In this case, there may be a number of offerings for one cultivar (i.e., different sizes and forms) where a firm sets a price for one size cultivar in relation to the other sizes and forms they offered for that same cultivar, as well as in relation to their other cultivar offerings and the expected prices of similar offerings set by their competitors. Therefore, we should expect to find a common variance and some covariance among certain clusters of errors such as those coming from the same firm. In fact, BreuschPagan tests indicated that heteroskedasticity was a problem for each of the species models. Since it is difficult to determine what type of error problems remain, we estimated of our set of seemingly unrelated regression equations using OLS and the Eicker-HuberWhite-sandwich covariance estimator. By using this method, we account for and estimate the within-model covariance matrices as well as the between-model covariances of parameter estimates. In this way, we use the inherent variance structures of the data to estimate robust standard errors for the regression statistics and, thus, minimize the risk of type I and type II errors.

\section{Results}

The results of the econometric model (Eq. [3]) for the pooled (using all observations) and the species (the data segmented by species groups) models are reported in Table 4. The results for control variables (i.e., market variables such as plant size, plant form, and plant phenotype variables) are available upon request from the authors. The hypothesis that OLS regression coefficients are equal across the species categories was tested using a structural test analogous to a Chow test. A Hausman-type test for seemingly unrelated estimation was used to test the hypothesis of equality of common coefficients across species groups. This test is well defined for models such as this, where there are price variance differences between species models. The Wald statistic for this test shows that the hypothesis could be rejected with virtually $100 \%$ confidence.

Since the semilog model is used, the regression coefficients were adjusted for interpretation. For continuous and integer measure variables (i.e., trademarked promos, promos, size container, length bareroot and caliper bareroot), the regression coefficient can be interpreted as the relative (proportional) change in price for a given absolute per unit change in that variable. For example, in the pooled model, the regression coefficient estimate for the number other promotions variable was 0.03018 , so this coefficient could be interpreted as a predicted price increase of $3.02 \%$ for each additional cultivar promotion (Table 4). For indicator and categorical variables, this article uses a coefficient transformation developed and advocated by Halvorsen and Palmquist (1980) for a more accurate interpretation of coefficients that do not define slope but capture differences in subgroup means between the reference category and the indicated group in dependent variable units $100[\exp (\beta)-1]$. For example, in the pooled model, the estimated coefficient of the indicator variable for year 2007 was 0.05455 , so the expected value of price for 
Table 4. Hedonic price regression results ( $\mathrm{R}^{2}$, number of observations) and converted coefficients for variables and firms analyzed for herbaceous and woody perennial plants.

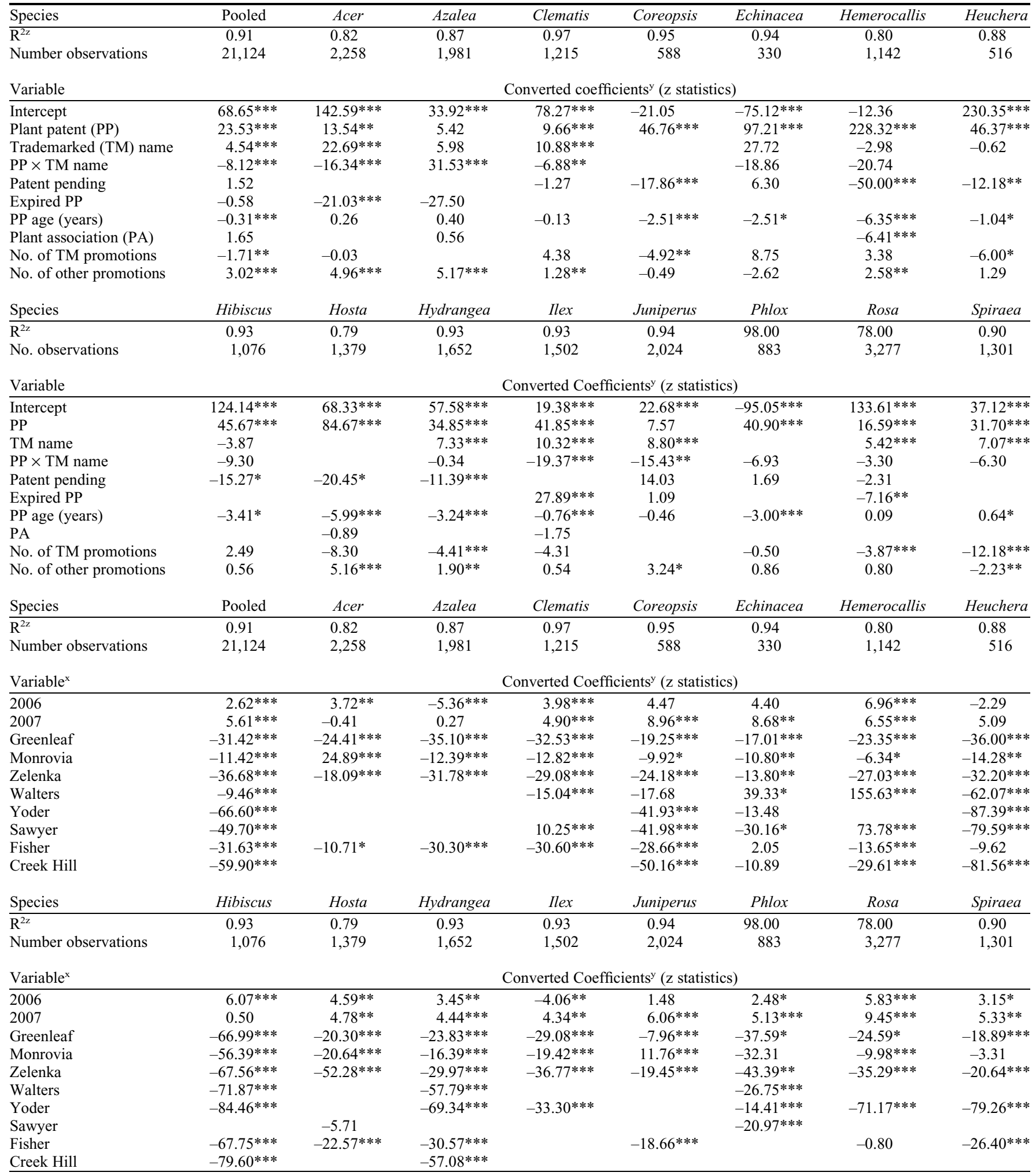

Reference group for year is 2005 and for firm is firm 3.

${ }^{\mathrm{z}} \mathrm{R}^{2}$ values are for the individually fitted models.

${ }^{y}$ Coefficients have been converted to be interpreted as the percent contribution to price per unit or with the presence of the attribute variable. $* * *, * *$, and * designate the $z$ statistics that indicate the coefficient is significantly different from zero at the 99,95 , and $90 \%$ confidence levels respectively.

2007 would be $5.61 \%$ higher than the reference year, 2005. Accordingly, all the numbers are raw regression coefficients that have been transformed (Table 4), so they can be interpreted as discussed.
Observations vary by species, e.g., the goodness-of-fit measure for each model, $\mathrm{R}^{2}$, varies from 0.78 (Rosa) to 0.98 (Phlox). These relatively high $\mathrm{R}^{2}$ values reflect the good fit of the models to the data. Overall, the regression results are satisfactory because most of the estimated coefficients have the expected signs and are statistically significantly different from zero.

The estimated price premiums for the plant patents with all but two of 15 species 
(Rhododendron and Juniperus) are significantly different from zero at least at the $95 \%$ confidence level. Plant patent price premiums are large but vary greatly, ranging from lows of statistical zero and $9.66 \%$ increases over the average price for Rhododendron and Clematis, respectively, to a high of a $228.32 \%$ increase over the average price for Hemerocallis. Overall, the plant patent price premium averages $23.53 \%$ for ornamental plants.

The statistical significance of results for the variables relevant to the age of the plant patent (i.e., patent pending, expired plant patent, and plant patent age) show how age affects the value of the plant patent over the different species (Table 4). The results for the plant patent age variable, indicate the plant patent decreases in value slowly, an average of $0.31 \%$ per year for all species. For six species (predominantly herbaceous perennials except for Hydrangea and Ilex), if the plant patent age coefficient is significantly different from zero, the plant patent decreases at higher than average rates. If the patent is pending, there is a significant and large percent decrease in the plant patent premium for Coreopsis (17.86\%, Table 4), Hemerocallis (51\%), Heuchera (12.18\%) and Hydrangea (11.39\%), and no significant effect on the other species. If the patent is expired, there is a significant and large percent discount in the average price for $\mathrm{Acer}$ $(21.03 \%)$, a significant and more modest decrease in price for Rosa (7.16\%) and, interestingly, a significant and large percent premium for Ilex $(27.89 \%)$.

The estimated price premiums for the trademark name for all but 4 of 12 applicable species (Rhododendron, Echinacea, Heuchera, and Hibiscus) were found to be significantly different from zero at least at the $99 \%$ confidence level. The average trademark name price premiums do not range as much as the plant patent, but range from lows of a $-2.98 \%$ decrease (Hemerocallis) and statistical $0 \%$ increase over the average price (Rhododendron, Heuchera, Hibiscus, respectively) to a high of $22.69 \%$ increase over the average price for Acer (Table 4). Overall, the name trademark price premium averages $4.54 \%$, which is considerably lower than plant patents.

Estimated results for the plant patent and the trademark name interaction coefficient allow for an evaluation the additional premium (or discount) when both IP forms are used. The estimated price premiums and discounts for the interaction between plant patents and name trademarks are statistically different from zero ( $95 \%$ confidence level) for only half of the 12 applicable species (Table 5). However, for these 12 species, the three IP coefficients are jointly significant at the $99 \%$ confidence level (Table 5). Five of these six are discounts and the largest is $20.74 \%$ for Hemerocallis. Only for Rhododendron did the addition of the trademark name create a rather high premium of $31 \%$ by comparison with the negative values of the other species. Overall, the addition of the trademark name to a plant patent creates an

Table 5. Ornamental plant average IP premiums and discounts $(\mathrm{PP}=$ plant patents, $\mathrm{TM}=$ trademarked name, $\mathrm{PP} \times \mathrm{TM}$, IP total) for the herbaceous and woody plants analyzed in this study.

\begin{tabular}{|c|c|c|c|c|}
\hline \multirow[b]{2}{*}{ Species } & \multicolumn{4}{|c|}{ Intellectual property premiums and discounts ${ }^{z}$} \\
\hline & $\mathrm{PP}$ & TM & $\mathrm{PP} \times \mathrm{TM}$ & IP total $^{y}$ \\
\hline All species & $23.53 * * *$ & $4.54 * * *$ & $-8.12 * * *$ & $19.95 * * *$ \\
\hline \multicolumn{5}{|l|}{ Woody perennials } \\
\hline Acer & $13.54 * *$ & $22.69 * * *$ & $-16.34 * * *$ & $19.89 * * *$ \\
\hline Clematis & $9.66 * * *$ & $10.88 * * *$ & $-6.88 * *$ & $13.67 * * *$ \\
\hline Hydrangea & $34.85 * * *$ & $7.33 * * *$ & -0.34 & $41.83 * * *$ \\
\hline Ilex & $41.85 * * *$ & $10.32 * * *$ & $-19.37 * * *$ & $32.80 * * *$ \\
\hline Juniperus & 7.57 & $8.80 * * *$ & $-15.43 * *$ & $0.94 * *$ \\
\hline Rhododendron & 5.42 & 5.98 & $31.53 * * *$ & $42.93 * * *$ \\
\hline Rosa & $16.59 * * *$ & $5.42 * * *$ & -3.30 & $18.72 * * *$ \\
\hline Spiraea & $31.70 * * *$ & $7.07 * * *$ & -6.30 & $32.47 * * *$ \\
\hline \multicolumn{5}{|c|}{ Herbaceous perennials } \\
\hline Coreopsis & $46.76 * * *$ & & & \\
\hline Echinacea & $97.21 * * *$ & 27.72 & -18.86 & $106.07 * * *$ \\
\hline Hemerocallis & $228.32 * * *$ & $-2.98 * * *$ & $-20.74 * * *$ & $204.60 * * *$ \\
\hline Heuchera & $46.37 * * *$ & -0.62 & & \\
\hline Hibiscus & $45.67 * * *$ & -3.87 & -9.30 & $32.50 * * *$ \\
\hline Hosta & $84.67 * * *$ & & & \\
\hline Phlox & $40.90 * * *$ & & -6.93 & $33.97 * * *$ \\
\hline
\end{tabular}

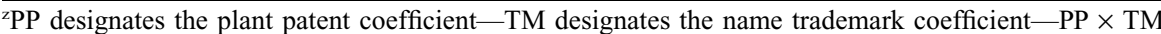
designates the interaction coefficient between PP and TM.

"The "IP Total" is the total of all three IP coefficients. ***, **, and * designate the $\mathrm{z}$ statistics that indicate the coefficient is significantly different from zero at the 99,95 , and $90 \%$ confidence levels respectivelythese significance levels for the "IP Total" are for joint significance on the individually fitted models.

average discount of $8.12 \%$. Between species, the trademark name variable and its interaction with the plant patent were more significant, both positively and negatively, for woody species (Table 5).

Since we can expect the premiums to be gained in each ornamental product classified by species to have some limit, the important question is: When a plant is patented, does the addition of a trademark name create a premium over those plants with just a plant patent? For 5/12 species (Hemerocallis, Hibiscus, Ilex, Juniperus, and Phlox) differences between plant patent premiums/ discounts and the total of all three premiums/ discounts are negative indicating an overall discount effect resulting from the addition of the name trademark to a patented plant. Across all species, this difference is negative and indicates an average $3.58 \%$ discount, resulting from the addition of a trademark name to a plant patent.

Across all species, trademarked promotions do not have a positive effect on price. On average, each additional trademarked promotion decreases a cultivar's value by $2.51 \%$. In contrast, other promotional information, such as the breeder's name or a popular cultivar, increases a cultivar's value by $3.02 \%$ with each addition. The promotional effects vary between species, but the signs of significant effects (except for Spiraea) agree with the pooled model. Wholesale buyers are influenced by more tangible promotional information associated with branding. These results, combined with the modest premiums and discounts resulting from the name trademark suggest that the value of branding may not have as much impact on price as firms might expect.

Since not every species is sold by each firm, the set of firm fixed effect variables are different for each species. The pooled model results for the firm fixed effect variables show that Bailey, the reference group (a firm specializing in woody perennials), generally commands higher prices than every other firm. For the pooled model, the firm differences from Bailey range from $56.39 \%$ to $79.6 \%$ and are generally larger than other firms specializing in herbaceous perennial plants.

Compared with Lesser's (1994) premium of $2.3 \%$ for PVP for soybeans, we find much higher premiums in the ornamental plant market for the varietal IP protection of plant patents. As expected, plant patent premiums vary considerably between species where the costs of producing and marketing new cultivars differ greatly and, while the lower premiums are for woody plants and the highest premiums are for herbaceous perennial species, there are no other clear patterns. The negative effects of the use of trademarks both for naming cultivars and for promotion programs were surprising, especially considering the summary statistics indicated that larger premiums may lie in those areas. While we did not expect the premiums of a trademark name added to a patented plant would create premiums as high as they would be on a nonpatented plant, we did not expect them to have a total discount effect as we found for some species.

\section{Discussion and Conclusions}

Given the diverse species mix, it is not surprising that the hedonic results are also diverse between species. This underscores the difficulties in ornamental plant production and marketing decision-making that agents face in an industry maintaining high levels of diversity and relatively small markets for each species. For breeders and propagators operating in a highly competitive and fluctuating industry, the ramifications of investments in plant patents and trademarked branding can be highly varied and difficult to determine. 
Plant patent premiums indicate significant value can be gained from their use by ornamental firms. Perhaps this is due to an industry that has evolved to effectively use plant patents and to enforce this long established form of protection (Aguirre, 2006). In addition, growers may recognize plant patents as a measure for a level of novelty and quality in new plants. Certainly, with the recent development of online resources, plant patents provide a reliable source of plant information to wholesale buyers of notable and tested plant attributes.

The effects of trademarks are intriguing and a subject deserving further research. The importance of branding and trademarks lies in its effectiveness with consumers, so the wholesale value comes from how wholesale market agents value their effectiveness. Use of branding and trademarks is new to horticultural industries, particularly, the ornamental plant industries. National brands have been around for just over a decade (Schoellhorn, 2009) and, still, the trademark notation, ${ }^{\mathrm{TM}}$ or ${ }^{\circledR}$, is not consistently included in nursery cultivar listings. Every plant category has its own market/branding issues (i.e., durable or nondurable goods, the number of agents handling a plant through the market chain, visibility of the label at point of purchase). Generally, the willingness to pay for brands in horticultural industries is low where consistency and quality are hard to maintain along the market chain (Jin et al., 2008). Inconsistencies in quality from year to year may devalue a brand to both growers and consumers.

Robustness and appearance of outdoor ornamental plants at point of purchase dominates consumer choice (Townsley-Brascamp and Marr, 1994) and impulse buying is common (Schoellhorn, 2009). A trademark is not usually observed by the consumer especially for healthy robust herbaceous plants. Jin et al. (2008) found that brands are more valuable for durable goods which are more likely to be purchased under conditions of high involvement where consumers spend more time on the decision process (Solomon and Stuart, 2003). In ornamentals, woody perennials, especially trees, are more like durable goods in contrast to herbaceous perennials which can be removed and replaced more easily and at less cost. For woody trees and shrubs, where there are higher costs and a longer expected life, the consumer is more likely to be motivated to find and inspect information on a tag that reveals a trademark.

Finally, it is important to note that the nomenclature of ornamentals plants can be very confusing with many marketed names in addition to a registered varietal name. The reasons for using a trademark name can be many if not misdirected (i.e., as an attractive selling name, an inexpensive way to protect the plant, to enhance the protection of the plant patent and to extend the life of a plant patent; Aguirre, 2006). As a result, trademarks as a signal to the buyer may have conflicting meanings and, when combined with a plant patent, may be perceived as a sign that the firm is trying too hard to create value.

The results of this research should be important to individuals and agencies with professional interests in the horticultural, legal, and economic areas. Policy makers and those affected by and seeking IP protection on plant cultivars in the United States can use this information in decision-making for the type(s) of IP to be employed on new cultivars. The ornamental industry that is increasingly engaged in branding activities will benefit from the knowledge of where these marketing plans may fall short of expectations by enabling more efficient allocation of resources toward the marketing of plant products.

\section{Literature Cited}

Aguirre, P. 2006. Protection: Plant patents, utility patents, plant breeders' rights, trademarks, branding, royalties, p. 81-112. In: N.O. Anderson (ed.). Flower breeding and genetics. Springer, Dordrecht, The Netherlands.

Ali, H.H., S. Lecocq, and M. Visser. 2008. The impact of Gurus: Parker grades and En Primeur wine prices. Econ. J. 118(529):F158-F173.

Alston, J.M. and R.J. Venner. 2002. The effects of the U.S. plant variety protection act on wheat genetic improvement. Res. Policy 31: 527-542.

Anderson, N.O. 2006. Chrysanthemum. Dendranthema $\times$ grandiflora Tzvelv, p. 389-437. In: N.O. Anderson (ed.). Flower breeding \& genetics: Issues, challenges, and opportunities for the 21 st century. Springer, Dordrecht, The Netherlands.

Belsley, D.A., E. Kuh, and R.E. Welsch. 1980. Regression diagnostics: Identifying influential data and sources of colinearity. Wiley, New York, NY.

Butler, L.J. and B.W. Marion. 1985. The impacts of patent protection on the U.S. seed industry and public plant breeding. College of Agricultural and Life Sciences, University of WisconsinMadison, Madison, WI.

Byron, R.P. and O. Ashenfelter. 1995. Predicting the quality of an unborn grange. The Economic Record 71(212):40-53.

Court, A.T. 1939. Hedonic price indexes, p. 99 117. In: The dynamics of automobile demand General Motors Corporation, New York, NY.

Diewert, W.E. 2003. Hedonic regressions: A review of some unresolved issues, 7th Meeting of the Ottawa Group. National Bureau of Economic Research, Paris, France.

Drew, J. 2010. The roots and fruits of plant varietal rights: An economic evaluation of intellectual property rights in the US horticultural sector. $\mathrm{PhD}$ dissertation, University of Minnesota. AAT 3408389.

Drew, J., N.O. Anderson, and D. Andow. 2010. Conundrums of a complex vector for invasive species control: A detailed examination of the horticultural industry. Biol. Invasions 12(8):2837-2851.

Estes, E.A. 1986. Estimating implicit prices of green pepper quality characteristics using hedonic techniques. J. Food Distrib. Res. 17(2):22-30.

Estes, E.A. and V.K. Smith. 1996. Price, quality, and pesticide related health risk considerations in fruit and vegetable purchases: A hedonic analysis of Tucson, Arizona supermarkets. J. Food Distrib. Res. 27(3):59-76.

Griliches, Z. 1961. Hedonic price indexes for automobiles: An econometric analysis of quality change, the price statistics of the federal government: 137-196. National Bureau of Economic Research, New York.

Halvorsen, R. and R. Palmquist. 1980. Interpretation of dummy variables in semilogarithmic equations. Amer. Econ. Rev. 70(3):474-475.

Hansen, L. and M. Knudson. 1996. Property right protection of reproducible genetic material. Rev. Agr. Econ. 18(3):403-414.

Huang, C.L. and L. Biing-Hwan. 2006. A hedonic analysis on the implicit values of fresh tomatoes. Paper presented at the International Association of Agricultural Economists Conference, Gold Coast, Australia.

Isaacson, R.T. and K. Allen (eds.). 2010. Plant Information Online. Andersen Horticultural Library, University of Minnesota.

Jerardo, A. 2007. Floriculture and nursery crops situation and outlook yearbook. U.S. Department of Agriculture, ERS Rep. FLO-2007, September. Washington, D.C.

Jin, Y.H., D. Zilberman, and A. Heiman. 2008. Choosing brands: Fresh produce versus other products. Amer. J. Agr. Econ. 90(2):463-475.

Knudson, M. and C.E. Pray. 1991. Plant variety protection, private funding, and public sector research priorities. Amer. J. Agr. Econ. 73(3): 882-886.

Lesser, W. 1994. Valuation of plant variety protection certificates. Rev. Agr. Econ. 16(2):231-238.

Lin, B.H., T.A. Smith, and C.L. Huang. 2008. Organic premiums of U.S. fresh produce. Renew. Agr. Food Syst. 23(3):208-216.

Maietta, O.W. 2003. The Hedonic Price of Fairtrade Coffee for the Italian Consumer. Paper presented at the International ConferenceAgricultural policy reform and the WTO: Where are we heading? Capri, Italy.

Palmquist, R.B. 1984. Estimating the demand for the characteristics of housing. Rev. Econ. Stat. 66(3):394-404

Penna, A.L. 1994. An analysis of the impact of plant breeders' rights legislation on the introduction of new varieties in U.K. horticulture. PhD Dissertation, University of London.

Perrin, R.K., K.A. Kunnings, and L.A. Ihnen. 1983. Some effects of the US Plant Variety Act of 1970. North Carolina State University, Raleigh, NC.

Ramsey, J.B. 1969. Tests for specification errors in classical linear least squares regression analysis. J. Royal Stat. Soc. 31(Series B):350-371.

Rangnekar, D. 2002. R\&D appropriability and planned obsolescence: Empirical evidence from wheat breeding in the UK (1960-1995). Ind. Corp Change 11(5):1011-1029.

Rosen, S. 1974. Hedonic prices and implicit markets: Product differentiation in pure competition. J. Polit. Econ. 82(1):34-55.

Schamel, G. 2003. International Wine Trade: Analyzing the value of reputation and quality signals. AAEA Annual Meeting, Berlin, Germany.

Schamel, G. and K. Anderson. 2003. Wine quality and varietal, regional and winery reputations: Hedonic prices for Australia and New Zealand. Econ. Rec. 79(246):257-269.

Schoellhorn, R. 2009. Strategies for plant introduction and market trends in the US. Acta Hort. 813:101-106.

Solomon, M.R. and E. Stuart. 2003. Marketing: Real people, real choices. 5 th ed. Prentice Hall, Upper Saddle River, NJ.

Stallmann, J.I. 1986. Impacts of the 1930 plant patent act on private fruit breeding investment. PhD Dissertation, Michigan State University.

Stanley, L.R. and J. Tschirhart. 1991. Hedonic prices for a nondurable good: The case of breakfast cereals. Rev. Econ. Stat. 73(3):537-541. 
Townsley-Brascamp, W. and N.E. Marr. 1994. Evaluation and analysis of consumer preferences for outdoor ornamental plants. Acta Hort. 391:199-206.

Triplett, J.E. 1990. Hedonic methods in statistical agency environments: An intellectual biopsy, p. 207-233. In: E.R. Berndt and J.E. Triplett (eds.). Fifty years of economic measurement: The Jubilee of the Conference on Research in
Income and Wealth. University of Chicago Press, Chicago.

Unwin, T. 1999. Hedonic price indexes and the qualities of wines. J. Wine Res. 10(2):95-104.

U.S. Department of Agriculture (USDA), National Agricultural Statistics Service. 2000. 1998 Census of Horticultural Specialties. In: 1997 Census of Agriculture; Vol. 3, Special Studies Part 2, March. Washington, DC.
U.S. Department of Labor (USDL), Bureau of Labor Statistics. 2010. Consumer Price Index History Table, February. Washington, DC.

Waugh, F.V. 1928. Quality factors influencing vegetable prices. J. Farm Econ. 10(2):185-196.

Zellner, A. 1962. An efficient method of estimating seemingly unrelated regressions and tests for aggregation bias. J. Amer. Stat. Assoc. 57: 348-368. 